\title{
Primary Immunodeficiency Diseases: Current and Emerging Therapeutics
}

\author{
Beatriz E. Marciano and Steven M. Holland* \\ Laboratory of Clinical Infectious Diseases, National Institute of Allergy and Infectious Diseases (NIAID), National Institutes \\ of Health (NIH), Bethesda, MD, United States
}

Primary immunodeficiency diseases (PID) result from defects in genes affecting the immune and other systems in many and varied ways (1, 2). Until the last few years, treatments have been largely supportive, with the exception of bone marrow transplantation. However, recent advances in immunobiology, genetics, and the explosion of discovery and commercialization of biologic modifiers have drastically altered the landscape and opportunities in clinical immunology. Therapeutic options and life expectancy of PID patients have also improved dramatically, in large part as a result of better prevention and treatment of infections as well as better understanding and treatment of autoimmune complications (3). As early-life infection-related mortality declines we should anticipate the emergence of other conditions that were previously not appreciated, including malignancies and degenerative disorders unmasked by increasing longevity (4). The

OPEN ACCESS

Edited by:

Mohamed-Ridha Barbouche, Institut Pasteur de Tunis, Tunisia

Reviewed by: Shigeaki Nonoyama, National Defense Medical College, Japan Ahmed Aziz Bousfiha, University of Hassan II Casablanca, Morocco

*Correspondence: Steven M. Holland smh@nih.gov

Specialty section: This article was submitted to Primary Immunodeficiencies,

a section of the journal

Frontiers in Immunology

Received: 11 May 2017

Accepted: 21 July 2017

Published: 09 August 2017

Citation:

Marciano BE and Holland SM (2017) Primary Immunodeficiency Diseases: Current and Emerging Therapeutics.

Front. Immunol. 8:937. doi: 10.3389/fimmu.2017.00937 genomic revolution has identified literally hundreds of new genetic etiologies of immune dysfunction, many of which are or will soon be eligible for targeted therapies. These emerging immunomodulatory agents represent new therapeutic options in PIDs (5).

Keywords: immunodeficiency, immune modulation, chronic granulomatous disease, leukocyte adhesion deficiency, interferon gamma

\section{THERAPY BASED ON CLINICAL PRACTICE}

\section{Prophylaxis}

Invasive bacterial, fungal, viral, and mycobacterial infections carry a high morbidity and mortality in the immunocompromised, and therefore, enormous effort has been directed at prevention. The advent of antibiotics in the last century was critical for the survival of patients with primary immunodeficiency disease (PID) (6). Even before the advent of antibiotic prophylaxis in advanced HIV infection, which transformed AIDS from a rapidly fatal to a more manageable disease, long-term prophylactic antibiotics were widely implemented in chronic granulomatous disease (CGD), with excellent effects (7). CGD also served as the first PID for which cytokine therapy with interferon gamma (IFN $\gamma$ ) (8) and antifungal prophylaxis was indicated and approved (9). The reasons that CGD played such a prominent role in the development and study of prophylaxis were that it was relatively survivable with medical management and bone marrow transplantation was relatively infrequent until recently. Therefore, a relatively large population of patients was able to participate in clinical trials, which markedly assisted the exploration and development of therapeutics. This paradigm has been missing from several other diseases, either because they are not as survivable or because bone marrow transplantation has been more aggressively practiced [e.g., severe combined immune deficiency, Wiskott-Aldrich syndrome (WAS), hyper-IgM syndrome]. For these reasons, many of the approaches discussed below will not have significant prospective clinical validation, making it necessary to rely upon mechanistic explanations and anecdotal reports. While it is likely that in the relatively near future treatments to replace (transplantation) or repair (gene therapy) the underlying 
B cell, T cell, and NK cell defects will be available, it is most likely that immunopathology will continue to be a prominent and recurring cause for PID patients to seek care.

The dual and somewhat conflicting demands of immune deficiency, with its recurrent and severe infections, and immune dysregulation, with its associated autoimmunity or autoinflammation, are now well appreciated as a hallmark of PID (10). This means that balancing close attention to infection susceptibility against needs for immunosuppression poses a major therapeutic challenge (11).

\section{Steroids}

Corticosteroids have been the backbone of immune modulation since their discovery in the 1930s and their use in rheumatoid arthritis (RA) in 1948 (12, 13). Despite their long use, their longterm toxicity remains significant and their specific mechanisms poorly understood. However, they continue to be a mainstay and first-line approach to immune modulation, especially when needed urgently. Their broad, rapid onset of effects on all the major actors of immune response (T, B, NK, neutrophils) as well as nominally non-immune pathways (e.g., wound healing, glucose metabolism, adrenal suppression) make them both highly effective and very difficult to clearly understand. Their significant complications such as polyphagia, diabetes, cataracts, osteopenia, and infections limit their utility and keep provider and patient anxiety levels high.

Despite these concerns, corticosteroids effectively manage the hollow viscera obstructive and inflammatory disorders in CGD and are surprisingly well tolerated with minimal additional infectious complications at low doses (14). In CGD, steroids have also been used in the treatment of "mulch pneumonitis," the acute inflammatory and necrotizing granulomatous lung disease that follows inhalation of organic matter, such as mulch, compost, dirt, or hay (15). In the CGD mouse model, fatal pulmonary granulomatous inflammation can be caused by either live Aspergillus hyphae, which cause invasive fungal infection, or, more surprisingly, by dead Aspergillus hyphae, which cause a severe fatal granulomatous response (16). Further, in CGD, steroids have been used in the setting of staphylococcal liver abscess, where they can largely obviate the need for surgery and better preserve long-term liver function (17). They have also helped with the management of necrotizing Nocardia pneumonias (18). Therefore, in CGD both invasive infection and hyper-inflammation vie as causes of morbidity and mortality and can be successfully managed with judicious coadministration of both steroids and antibiotics.

\section{Cytokine Therapy}

\section{Interferon Alpha (IFN $\alpha$ )}

Defects in the TLR3 pathway have been clearly defined as causes of recurrent herpes simplex encephalitis (HSE) in children due to mutations in TLR3, UNC-93B, TRIF, TBK-1, TRAF-3, and IRF3 (19). All of these genes converge on the pathways for neuronal IFN $\alpha$ production, mutations in which put neurons at risk for uncontrolled herpesviral replication. Importantly, in some of these defects (TBK1, TLR3, TRAF3) peripheral blood mononuclear cell IFN $\alpha$ production is normal, even though fibroblast and neuronal production are impaired. Therefore, the search for defects involved in HSE should be done genetically and not based entirely on the in vitro responses found in peripheral blood samples. Exogenous IFN $\alpha$ or IFN $\beta$ therapy clearly rescue the viral phenotype in vitro, suggesting that IFN $\alpha$ or IFN $\beta$ therapy might be useful in cases of HSE associated with defects in the TLR3 pathway $(20,21)$. Whether IFN $\alpha$ therapy might have activity in cases of HSE without defects in the TLR3-IRF3 pathway is unclear at this point.

\section{Interferon Gamma (IFN $\gamma$ )}

After its early cloning and production, expectations for the clinical applications of IFN $\gamma$ were high. Unfortunately, very few of those expectations were realized. However, the observation that IFN $\gamma$ increased superoxide production from monocytederived macrophages in vitro led to interest in using it in therapy for chronic granulomatous disease (CGD). An international, prospective, randomized double-blind trial in CGD patients showed clear reduction in severe infections in the IFN $\gamma$ (50 $\mu \mathrm{g} / \mathrm{m}^{2}$ subcutaneously three times weekly) group without exacerbation of granulomatous or inflammatory complications (22). IFN $\gamma$ is essential for the killing of many intracellular microbes and has been used to enhance anti-mycobacterial immunity in patients with partial dominant IFN $\gamma$ receptor 1 deficiency and chemotherapy-resistant mycobacterial infection (23). Higher doses of IFN $\gamma\left(200 \mu \mathrm{g} / \mathrm{m}^{2}\right)$ have been used in those with mycobacterial infections in the dominant partial forms of IFN $\gamma$ receptor deficiency and in recessive IL12R $\beta 1$ deficiency (24).

\section{THERAPY BASED ON MECHANISM}

\section{Interleukin-2}

Interleukin-2 is secreted from $\mathrm{T}$ cells and supports $\mathrm{T}$ cell proliferation, NK cell activation, and can promote activation-induced cell death $(25,26)$. However, at low does, recombinant IL-2 has also been shown to selectively increase $\mathrm{T}$ regulatory (Treg) cells. In the WAS, IL-2 therapy was recognized to enhance killing activity in vitro (27). In a prospective study WAS patients responded to low-dose IL-2 $\left(0.5 \mathrm{MU} / \mathrm{m}^{2}\right.$ for 5 days every 3 weeks) with modest increases in lymphocyte counts. However, consistent with the narrow dose range for many cytokines, at the $1 \mathrm{MU}$ dose several patients had worsened thrombocytopenia (28). In the setting of bone marrow transplantation low-dose and very low-dose IL-2 have been shown to increase Treg cells, but their long-term value in preventing graft-versus-host disease (GVHD) is still being determined (29).

\section{Cell Depletion CD 20}

Rituximab (anti-CD20) is active in the treatment of lymphoma and in many autoimmune diseases, presumably through B cell depletion and also through disruption of autoantibody production. However, depletion of CD20+ B cells also removes potent antigen presenting cells, so it may have more than one mechanism of action. Improved quality of life has been observed in those with B-cell class-switch defects (hyper-IgM syndrome), who received 
rituximab for the treatment of autoimmune manifestations and generalized lymphadenopathy (30). Rituximab has been used as immunomodulatory therapy, especially as part of the treatment of granulomatous lymphocytic interstitial lung disease (31) in CVID as well as in CVID-associated autoimmune cytopenias (32-34). In patients with anti-IFN $\gamma$ autoantibodies who have severe disseminated infections with intracellular pathogens, especially non-tuberculous mycobacteria, rituximab has helped to reduce antibody levels allowing clearance of infection (35).

\section{Cytokine Antagonists}

\section{Anti-IL-17 and Anti-p40 (Anti-IL-12/23)}

IL-17 is an important mediator of inflammation, especially at epithelial surfaces. It is itself induced in CD $4+\mathrm{T}$ cells by IL-23 and in turn induces the generation of G-CSF and IL-22. IL-17 neutralization has profoundly beneficial effects on the clinical courses of psoriasis and colitis (36). IL-23 is formed by the heterodimerization of IL-23p19 and IL-12p40, while IL-12 is formed by the heterodimerization of IL-12p35 and IL-12p40. In a mouse model of colitis, neutralization of IL-23 using an IL-23specific anti-p19 antibody significantly alleviated both emerging and established colitis, through the downstream inhibition of IL-17 expression, leading to diminished neutrophil infiltration (37). One case of severe CGD colitis treated with ustekinumab (anti-p40, the common chain of IL-12 and IL-23) showed clinical improvement but developed a severe infection (38).

Leukocyte adhesion defect (LAD) 1 is characterized by a severe periodontal disease and premature loss of teeth. Moutsopoulos et al. showed that excessive IL-17 expressing T cells in periodontal tissue is responsible for the inflammation and bone loss in human and mouse models of LAD1. These observations support targeting IL17 production through inhibition of IL-12/23 p40 (39).

\section{IL-1}

IL-1 is induced in response to numerous inflammatory stimuli and is the critical mediator of fever; it was previously known as "endogenous pyrogen." Its natural antagonist, IL1RA, inhibits IL-1's activation of its receptor and, therefore, blocks IL1-mediated inflammation. IL-1 is generated from proIL-1 by the action of the IL-1 inflammasome, mediated by NLRP3, previously known as CIAS. Gain-of-function (GOF) mutations in NLRP3 lead to autoinflammatory diseases, so-called because they do not depend on antigen-specific triggers or $\mathrm{T}$ or $\mathrm{B}$ responses. Anakinra has been used extensively in disorders of inflammation. de Luca et al. showed that inhibition of IL-1 receptor activation using the receptor blocker anakinra resulted in inflammasome inactivation, restoration of autophagy, improvement in colitis, and protection from invasive aspergillosis in $\mathrm{p} 47$ phox ${ }^{-1-}$ mice. Studies in human subjects are essential to derive data on safety, dosage, and duration and complete efficacy of anakinra therapy in patients with CGD.

\section{IL-6}

IL-6 is a cytokine that induces signal transducer and activator of transcription (STAT) 3 phosphorylation and leads to fever and the acute phase response. Interestingly, it is also a myokine that is produced by muscle during activity. IL6 is elevated in RA and has been successfully targeted in that disease by tocilizumab, which inhibits downstream STAT3-mediated effects. In the disease caused by GOF STAT3 mutations, signaling is pathologically augmented, leading to fever, arthritis, rashes and lung disease. Milner et al. showed that tocilizumab led to marked improvement of peripheral arthritis and scleroderma-like skin lesions in a patient who had failed multiple other immunosuppressive therapies (40).

\section{Signal Blockade CTLA4}

CTLA4 is expressed on Treg cells and activated T cells, providing an inhibitory signal to effector $\mathrm{T}$ lymphocytes through its binding to CD80/CD86. Therefore, reduced CTLA4 expression leads to reduced Treg activity, which in turn leads to autoimmunity. CTLA4 deficiency is characterized by cytopenias and the triad of granulomatous brain lesions, granulomatous lung lesions and gut involvement; these manifestations can be separate or together, and either immunodeficient or autoimmune phenomena may predominate. Abatacept is a protein formed by the fusion of the Fc domain of IgG1 to the extracellular domain of CTLA4, thereby mimicking the binding of CTLA4 to CD80/CD86 and helping to tamp down autoimmunity. Lee et al. reported the effectiveness of abatacept in an adolescent girl with a mutation in CTLA4 and severe gut and other disease (41).

\section{T Cell-Directed Therapies}

In ALPS-associated autoimmune cytopenias steroids are the first line of treatment, followed by mycophenolate mofetil (a prodrug of mycophenolic acid that inhibits inosine monophosphate dehydrogenase and suppresses $\mathrm{T}$ and $\mathrm{B}$ cells) and sirolimus [an mechanistic target of rapamycin (mTOR) inhibitor] that more effectively targets double-negative T cells $(32,42)$.

In other PIDs, such as CGD, methotrexate and cyclosporine have been used to control T-cell-mediated complications. Hydroxychloroquine, a moderately effective but less immunosuppressive drug, can be used as a single drug therapy or in combination with low-dose steroids. Hydroxychloroquine may enhance CLTLA4 expression through the inhibition of lysosomal CTLA4 degradation (43).

\section{Janus-Associated Kinase/STAT Inhibitors}

Gain-of-function mutations in STAT1 lead to sustained levels of phosphorylation of STAT1 upon stimulation, which result in increased expression of interferon-simulated genes. Autoimmunity and infection caused by STAT1 GOF mutations are thought to be the result of dysregulated $\mathrm{T}$ cell responses. Janus kinase inhibitors may be effective targeted treatments for long-term disease control of severely affected patients for whom hematopoietic stem cell transplantation is not available (44-46). The experience with transplantation for STAT1 GOF has so far been disappointing, suggesting that there are complex issues that will need novel approaches in terms of preparative regimen, in particular (47).

\section{mTOR Inhibitors}

Mechanistic Target of Rapamycin is a serine/threonine protein kinase that regulates a dizzying array of cellular and metabolic 
activities, especially including $\mathrm{T}$ cell proliferation. Conditions that constitutively or aberrantly activate the mTOR pathway lead to excess signaling, and are associated with abnormal cell proliferation and autoimmunity. Rapamycin is a small molecule that blocks mTOR activity and has found extensive clinical application in the maintenance of transplant tolerance. It has also achieved good clinical responses in patients with immune dysregulation, polyendocrinopathy, enteropathy, X-linked (IPEX) syndrome, probably related to the decrease in proliferation of $\mathrm{T}$ effector cells with relative preservation of Treg cells. It leads to reduction in hepatosplenomegaly and lymphadenopathy, improvement in naive $\mathrm{T}$ cell counts, and restitution of lymphocyte IL-2 secretion $(48,49)$.

In activating mutations in PIK3CD, Lucas et al. demonstrated that rapamycin restored the abundance of naive $\mathrm{T}$ cells, largely "rescued" the in vitro $\mathrm{T}$ cell defects and improved the clinical course (50). In LRBA deficiency, which is associated with impaired CTLA4 display due to LRBA's role in CTLA4 recycling, the CTLA4 mimetic abatacept caused dramatic and sustained improvement (43).

\section{Apoptosis}

Programmed cell death protein 1, PD-1, binds to PD-1 ligand, PDL-1, and downregulates the activity of inflammatory $\mathrm{T}$ cells. This interaction forms the basis of one of the immune checkpoints, a node at which immune reactivity can either be encouraged (PD-1 inhibition) or diminished (PD-1 expression). This fundamental recognition has served as the basis for the newer immune therapies in cancer, which use PD-1 inhibition to disinhibit high PD-1 expression leading to antitumor immune response. High PD-1 expression is generally associated with exhaustion of $\mathrm{T}$ cells, such as during chronic viral infections, and is associated with poor responses to antigen activation. Importantly, blockade of this PD-1/PD-1-ligand interaction restores antigen-specific responses in vitro (51). PD-1 receptor blockade increased JC virus-specific T-cell immune responses in a subgroup of progressive multifocal leukoencephalopathy (PML) patients in vitro, suggesting that this pathway might be important in the control of JC virus-associated PML (52).

\section{Miscellaneous Agents Magnesium}

LOF mutations in the gene encoding the X-linked magnesium transporter 1 (MAGT1) result in an immunodeficiency characterized by EBV infection and lymphoma (XMEN), due to

\section{REFERENCES}

1. Stray-Pedersen A, Sorte HS, Samarakoon P, Gambin T, Chinn IK, Coban Akdemir ZH, et al. Primary immunodeficiency diseases: genomic approaches delineate heterogeneous Mendelian disorders. J Allergy Clin Immunol (2017) 139:232-45. doi:10.1016/j.jaci.2016.05.042

2. Bousfiha AA, Jeddane L, Ailal F, Benhsaien I, Mahlaoui N, Casanova J-L, et al. Primary immunodeficiency diseases worldwide: more common than generally thought. J Clin Immunol (2013) 33(1):1-7. doi:10.1007/s10875-012-9751-7

3. Notarangelo LD. Primary immunodeficiencies. J Allergy Clin Immunol (2010) 125(2 Suppl 2):S182-94. doi:10.1016/j.jaci.2009.07.053

4. Rezaei N, Hedayat M, Aghamohammadi A, Nichols KE. Primary immunodeficiency diseases associated with increased susceptibility to viral infections impaired magnesium-dependent intracellular signaling, which is especially important in NK cell function (53). Treatment with high-dose magnesium, supplied by the oral preparation magnesium threanate has been able to restore NK activity and reduce EBV viral loads in a small number of cases.

\section{Pioglitazone}

Peroxisome proliferator-activated receptor $\gamma(\operatorname{PPAR} \gamma)$ is a central mediator of metabolic responses, which has made it a target for endocrine therapies. PPAR $\gamma$ is involved in numerous cellular pathways, including reactive oxygen species (ROS) generation in mitochondria, fatty acid metabolism, and gluconeogenesis. Activation of intracellular PPAR $\gamma$ by agonists such as pioglitazone improved neutrophil ROS production and enhanced microbicidal action against Staphylococcus aureus in a murine CGD model (54). Apparently, pioglitazone leads to increased mitochondrial ROS, which then supplements the intracellular killing of certain microbes. Pioglitazone may also regulate other pathways, including IL-17, which is aberrantly high in CGD.

\section{STATE-OF-THE-ART TREATMENTS}

Chronic and refractory viral infections remain a cause of significant mortality both before and after HSCT in patients with PID. Reconstitution of T cell immunity is critical for control of viral infections. Adoptive immunotherapy with virus-specific T lymphocytes (VSTs) is an attractive option for addressing the underlying impaired $\mathrm{T}$ cell immunity (55). Infusion reactions are uncommon, mild and likely related to the cryopreservation additive rather than the VST themselves. To date, with limited phase 1 and 2 studies, cytokine release syndrome has not been described, though it remains a theoretical risk, particularly in patients with disseminated viral disease. And also it is unclear if the rate of GVHD in those receiving VST therapy is different from the background rate of GVHD in patients undergoing HSCT.

\section{AUTHOR CONTRIBUTIONS}

BM drafted and edited the manuscript. SH conceived and edited the final version.

\section{FUNDING}

This work supported by the Division of Intramural Research, National Institute of Allergy and Infectious Diseases.

and malignancies. J Allergy Clin Immunol (2011) 127:1329-41. doi:10.1016/j. jaci.2011.02.047

5. Vignesh P, Rawat A, Singh S. An update on the use of immunomodulators in primary immunodeficiencies. Clin Rev Allergy Immunol (2017) 52(2):287-303. doi:10.1007/s12016-016-8591-2

6. Ochs HD, Hitzig WH. History of primary immunodeficiency diseases. Curr Opin Allergy Clin Immunol (2012) 12(6):577-87. doi:10.1097/ ACI.0b013e32835923a6

7. Kuruvilla M, de la Morena MT. Antibiotic prophylaxis in primary immune deficiency disorders. JAllergy Clin Immunol Pract (2013) 1:573-82. doi:10.1016/j.jaip.2013.09.013

8. Gallin JI, Malech HL, Curnutte J, Quie P, Jaffe H, Ezekowitz R. A controlled trial of interferon gamma to prevent infection in chronic granulomatous 
disease. N Engl JMed (1991) 324:509-16. doi:10.1056/NEJM1991022 13240801

9. Gallin JI, Alling DW, Malech HL, Wesley R, Koziol D, Marciano B, et al. Itraconazole to prevent fungal infections in chronic granulomatous disease. N Engl J Med (2003) 348:2416-22. doi:10.1056/NEJMoa021931

10. Walter JE, Farmer JR, Foldvari Z, Torgerson TR, Cooper MA. Mechanismbased strategies for the management of autoimmunity and immune dysregulation in primary immunodeficiencies. J Allergy Clin Immunol Pract (2016) 4:1089-100. doi:10.1016/j.jaip.2016.08.004

11. Kuijpers T, Lutter R. Inflammation and repeated infections in CGD: two sides of a coin. Cell Mol Life Sci (2012) 69:7-15. doi:10.1007/s00018-011-0834-z

12. Benedek TG. History of the development of corticosteroid therapy. Clin Exp Rheumatol (2011) 29(5 Suppl 68):S5-12.

13. Hench PS, Kendall EC, Slocumb CH, Polley HF. The effect of a hormone of the adrenal cortex (17-hydroxy-11-dehydrocorticosterone: compound E) and of pituitary adrenocortical hormone in arthritis: preliminary report. Ann Rheum Dis (1949) 8(2):97-104.

14. Chin TW, Stiehm ER, Falloon J, Gallin JI. Corticosteroids in treatment of obstructive lesions of chronic granulomatous disease. J Pediatr (1987) 111(3):349-52. doi:10.1016/S0022-3476(87)80452-3

15. Siddiqui S, Anderson VL, Hilligoss DM, Abinun M, Kuijpers TW, Masur H, et al. Fulminant mulch pneumonitis: an emergency presentation of chronic granulomatous disease. Clin Infect Dis (2007) 45:673-81. doi:10.1086/ 520985

16. Morgenstern DE, Gifford MA, Li LL, Doerschuk CM, Dinauer MC. Absence of respiratory burst in $\mathrm{X}$-linked chronic granulomatous disease mice leads to abnormalities in both host defense and inflammatory response to Aspergillus fumigatus. J Exp Med (1997) 185:207-18. doi:10.1084/jem.185.2.207

17. Leiding JW, Freeman AF, Marciano BE, Anderson VL, Uzel G, Malech HL, et al. Corticosteroid therapy for liver abscess in chronic granulomatous disease. Clin Infect Dis (2012) 54(5):694-700. doi:10.1093/cid/cir896

18. Freeman AF, Marciano BE, Anderson VL, Uzel G, Costas C, Holland SM. Corticosteroids in the treatment of severe Nocardia pneumonia in chronic granulomatous disease. Pediatr Infect Dis J (2011) 30(9):806-8. doi:10.1097/ INF.0b013e318218181d

19. Maglione PJ, Simchoni N, Cunningham-Rundles C. Toll-like receptor signaling in primary immune deficiencies. Ann N Y Acad Sci (2015) 1356:1-21. doi:10.1111/nyas. 12763

20. Lafaille FG, Pessach IM, Zhang SY, Ciancanelli MJ, Herman M, Abhyankar A, et al. Impaired intrinsic immunity to HSV-1 in human iPSC-derived TLR3deficient CNS cells. Nature (2012) 491:769-73. doi:10.1038/nature11583

21. McGlasson S, Jury A, Jackson A, Hunt D. Type I interferon dysregulation and neurological disease. Nat Rev Neurol (2015) 11:515-23. doi:10.1038/ nrneurol.2015.143

22. Weening RS, Leitz GJ, Seger RA. Recombinant human interferon-gamma in patients with chronic granulomatous disease - European follow up study. Eur J Pediatr (1995) 154:295-8. doi:10.1007/s004310050292

23. Newport MJ, Huxley CM, Huston S, Hawrylowicz CM, Oostra BA, Williamson R, et al. A mutation in the interferon-gamma-receptor gene and susceptibility to mycobacterial infection. N Engl J Med (1996) 335(26):1941-9. doi:10.1056/NEJM199612263352602

24. Alangari AA, Al-Zamil F, Al-Mazrou A, Al-Muhsen S, Boisson-Dupuis S, Awadallah S, et al. Treatment of disseminated mycobacterial infection with high-dose IFN-gamma in a patient with IL-12Rbetal deficiency. Clin Dev Immunol (2011) 2011:691956. doi:10.1155/2011/691956

25. Cook KD, Waggoner SN, Whitmire JK. NK cells and their ability to modulate T cells during virus infections. Crit Rev Immunol (2014) 34:359-88. doi:10.1615/CritRevImmunol.2014010604

26. Bachmann MF, Oxenius A. Interleukin 2: from immunostimulation to immunoregulation and back again. EMBO Rep (2007) 8:1142-8. doi:10.1038/ sj.embor.7401099

27. Azuma H, Sakata H, Saijyou M, Okuno A. Effect of interleukin 2 on intractable herpes virus infection and chronic eczematoid dermatitis in a patient with Wiskott-Aldrich syndrome. Eur J Pediatr (1993) 152:998-1000. doi:10.1007/ BF01957224

28. Jyonouchi S, Gwafila B, Gwalani LA, Ahmad M, Moertel C, Holbert C, et al. Phase I trial of low-dose interleukin 2 therapy in patients with Wiskott-Aldrich syndrome. Clin Immunol (2017) 179:47-53. doi:10.1016/j.clim.2017.02.001
29. Kennedy-Nasser AA, Ku S, Castillo-Caro P, Hazrat Y, Wu MF, Liu H, et al. Ultra low-dose IL-2 for GVHD prophylaxis after allogeneic hematopoietic stem cell transplantation mediates expansion of regulatory $\mathrm{T}$ cells without diminishing antiviral and antileukemic activity. Clin Cancer Res (2014) 20:2215-25. doi:10.1158/1078-0432.CCR-13-3205

30. Hennig C, Baumann U, Ilginus C, Horneff G, Foell J, Hansen G. Successful treatment of autoimmune and lymphoproliferative complications of patients with intrinsic B-cell immunodeficiencies with rituximab. Br J Haematol (2010) 148:445-8. doi:10.1111/j.1365-2141.2009.07987.x

31. Chase NM, Verbsky JW, Hintermeyer MK, Waukau JK, Tomita-Mitchell A, Casper JT, et al. Use of combination chemotherapy for treatment of granulomatous and lymphocytic interstitial lung disease (GLILD) in patients with common variable immunodeficiency (CVID). J Clin Immunol (2013) 33:30-9. doi:10.1007/s10875-012-9755-3

32. Rao VK, Price S, Perkins K, Aldridge P, Tretler J, Davis J, et al. Use of rituximab for refractory cytopenias associated with autoimmune lymphoproliferative syndrome (ALPS). Pediatr Blood Cancer (2009) 52(7):847-52. doi:10.1002/ pbc. 21965

33. Cunningham-Rundles C. Key aspects for successful immunoglobulin therapy of primary immunodeficiencies. Clin Exp Immunol (2011) 164(Suppl 2):16-9. doi:10.1111/j.1365-2249.2011.04390.x

34. Gobert D, Bussel JB, Cunningham-Rundles C, Galicier L, Dechartres A, Berezne A, et al. Efficacy and safety of rituximab in common variable immunodeficiency-associated immune cytopenias: a retrospective multicentre study on 33 patients. Br J Haematol (2011) 155(4):498-508. doi:10.1111/j.1365-2141.2011.08880.x

35. Browne SK, Zaman R, Sampaio EP, Jutivorakool K, Rosen LB, Ding L, et al. Anti-CD20 (rituximab) therapy for anti-IFN-gamma autoantibody-associated nontuberculous mycobacterial infection. Blood (2012) 119:3933-9. doi:10.1182/blood-2011-12-395707

36. Yamagata T, Skepner J, Yang J. Targeting Th17 effector cytokines for the treatment of autoimmune diseases. Arch Immunol Ther Exp (Warsz) (2015) 63:405-14. doi:10.1007/s00005-015-0362-x

37. Wang R, Hasnain SZ, Tong H, Das I, Che-Hao Chen A, Oancea I, et al. Neutralizing IL-23 is superior to blocking IL-17 in suppressing intestinal inflammation in a spontaneous murine colitis model. Inflamm Bowel Dis (2015) 21:973-84. doi:10.1097/MIB.0000000000000353

38. Butte MJ, Park KT, Lewis DB. Treatment of CGD-associated colitis with the IL-23 blocker ustekinumab. J Clin Immunol (2016) 36:619-20. doi:10.1007/ s10875-016-0318-x

39. Moutsopoulos NM, Konkel J, Sarmadi M, Eskan MA, Wild T, Dutzan N, et al. Defective neutrophil recruitment in leukocyte adhesion deficiency type I disease causes local IL-17-driven inflammatory bone loss. Sci Transl Med (2014) 6:229ra40. doi:10.1126/scitranslmed.3007696

40. Milner JD, Vogel TP, Forbes L, Ma CA, Stray-Pedersen A, Niemela JE, et al. Early-onset lymphoproliferation and autoimmunity caused by germline STAT3 gain-of-function mutations. Blood (2015) 125:591-9. doi:10.1182/ blood-2014-09-602763

41. Lee S, Moon JS, Lee CR, Kim HE, Baek SM, Hwang S, et al. Abatacept alleviates severe autoimmune symptoms in a patient carrying a de novo variant in CTLA-4. J Allergy Clin Immunol (2016) 137:327-30. doi:10.1016/j.jaci.2015. 08.036

42. Teachey DT, Greiner R, Seif A, Attiyeh E, Bleesing J, Choi J, et al. Treatment with sirolimus results in complete responses in patients with autoimmune lymphoproliferative syndrome. $\mathrm{Br}$ J Haematol (2009) 145(1):101-6. doi:10.1111/j.1365-2141.2009.07595.x

43. Lo B, Zhang K, Lu W, Zheng L, Zhang Q, Kanellopoulou C, et al. Patients with LRBA deficiency show CTLA4 loss and immune dysregulation responsive to abatacept therapy. Science (2015) 349(6246):436-40. doi:10.1126/science. aaa1663

44. Weinacht KG, Charbonnier LM, Alroqi F, Plant A, Qiao Q, Wu H, et al. Ruxolitinib reverses dysregulated $\mathrm{T}$ helper cell responses and controls autoimmunity caused by a novel signal transducer and activator of transcription 1 (STAT1) gain-of-function mutation. J Allergy Clin Immunol (2017) 139(5):1629-40.e2. doi:10.1016/j.jaci.2016.11.022

45. Harel S, Higgins CA, Cerise JE, Dai Z, Chen JC, Clynes R, et al. Pharmacologic inhibition of JAK-STAT signaling promotes hair growth. Sci Adv (2015) 1:e1500973. doi:10.1126/sciadv.1500973 
46. Xing L, Dai Z, Jabbari A, Cerise JE, Higgins CA, Gong W, et al. Alopecia areata is driven by cytotoxic T lymphocytes and is reversed by JAK inhibition. Nat Med (2014) 20:1043-9. doi:10.1038/nm.3645

47. Leiding JW, Okada S, Hagin D, Abinun M, Shcherbina A, Balashov DN, et al. Hematopoietic stem cell transplantation in patients with gain of function STAT1 mutation. J Allergy Clin Immunol (2017). doi:10.1016/j.jaci.2017.03.049

48. Bacchetta R, Barzaghi F, Roncarolo MG. From IPEX syndrome to FOXP3 mutation: a lesson on immune dysregulation. Ann N Y Acad Sci (2016). doi:10.1111/nyas.13011

49. Yong PL, Russo P, Sullivan KE. Use of sirolimus in IPEX and IPEX-like children. J Clin Immunol (2008) 28:581-7. doi:10.1007/s10875-008-9196-1

50. Lucas CL, Kuehn HS, Zhao F, Niemela JE, Deenick EK, Palendira U, et al. Dominant-activating germline mutations in the gene encoding the $\mathrm{PI}(3) \mathrm{K}$ catalytic subunit p110delta result in T cell senescence and human immunodeficiency. Nat Immunol (2014) 15:88-97. doi:10.1038/ni.2771

51. Hong JJ, Amancha PK, Rogers K, Ansari AA, Villinger F. Re-evaluation of PD-1 expression by $\mathrm{T}$ cells as a marker for immune exhaustion during SIV infection. PLoS One (2013) 8:e60186. doi:10.1371/journal.pone.0060186

52. Tan CS, Bord E, Broge TA Jr, Glotzbecker B, Mills H, Gheuens S, et al. Increased program cell death-1 expression on T lymphocytes of patients with progressive multifocal leukoencephalopathy. J Acquir Immune Defic Syndr (2012) 60:244-8. doi:10.1097/QAI.0b013e31825a313c
53. Ravell J, Chaigne-Delalande B, Lenardo M. X-linked immunodeficiency with magnesium defect, Epstein-Barr virus infection, and neoplasia disease: a combined immune deficiency with magnesium defect. Curr Opin Pediatr (2014) 26:713-9. doi:10.1097/MOP.0000000000000156

54. Fernandez-Boyanapalli RF, Frasch SC, Thomas SM, Malcolm KC, Nicks M, Harbeck RJ, et al. Pioglitazone restores phagocyte mitochondrial oxidants and bactericidal capacity in chronic granulomatous disease. J Allergy Clin Immunol (2015) 135:517-27.e12. doi:10.1016/j.jaci.2014.10.034

55. McLaughlin LP, Bollard CM, Keller M. Adoptive T cell immunotherapy for patients with primary immunodeficiency disorders. Curr Allergy Asthma Rep (2017) 17:3. doi:10.1007/s11882-017-0669-2

Conflict of Interest Statement: The authors declare that the research was conducted in the absence of any commercial or financial relationships that could be construed as a potential conflict of interest.

Copyright (c) 2017 Marciano and Holland. This is an open-access article distributed under the terms of the Creative Commons Attribution License (CC BY). The use, distribution or reproduction in other forums is permitted, provided the original author(s) or licensor are credited and that the original publication in this journal is cited, in accordance with accepted academic practice. No use, distribution or reproduction is permitted which does not comply with these terms. 